\title{
The clinical and metabolic significance of jejunal diverticula
}

\author{
W. T. COOKE, E. V. COX, D. J. FONE, \\ M. J. MEYNELL, AND R. GADDIE \\ From the General Hospital, Birmingham
}

EDITORIAL SYNOPSIS A study of 33 patients with jejunal diverticula showed that all except four had symptoms or metabolic upsets attributable to the presence of the diverticula. A disturbance of vitamin B12 metabolism or absorption was found in 16 patients and neuropathy was found in 12 patients. It is considered that abnormal bacterial activity in the small intestine is an important factor in these patients.

According to Walker (1954), Astley Cooper in 1807 was the first to describe diverticula of the jejunum. There were descriptions of the condition in the anatomy books of the day including that by Meckel (1812). In 1881, William Osler described a 65-yearold man with 53 jejunal diverticula ranging 'in size from a cherry to a large apple'. For many years, he had had colicky abdominal pains and borborygmi so noisy that they caused him to withdraw from company after meals. He died 'of an acute enteric attack with melaena' and though Osler recognized the diverticula as the cause of the symptoms he did not associate them with the haemorrhage. Relatively few cases were published during the next 50 years and in 1906 Gordinier and Sampson recorded the first patient in whom the diagnosis was made during life, at operation for intestinal obstruction. In 1920, the first radiological demonstration of jejunal diverticula was made by Case who 10 years earlier had detected duodenal diverticula by the same means. During the period 1920 to 1950 much of the literature was devoted to describing complications of jejunal diverticula and a feature was the reluctance of many authors to attribute any other symptoms to them. For example, Harvey and Murphy (1933) in describing a patient with pernicious anaemia without achlorhydria, remarked on the radiographic demonstration of multiple diverticula but did not associate them with the anaemia. In fact, despite the symptoms of abdominal pain, diarrhoea, and oedema, the diverticula were not mentioned in the subsequent necropsy report.

During this same period, research into the aetiology of pernicious anaemia had uncovered the association of a similar haematological picture with intestinal strictures and anastomoses (Faber, 1895). In 1939 Barker and Hummel reviewed 59 cases from the literature and added two of their own: one of this series had multiple intestinal diverticula. Experimentally Cameron, Watson, and Witts (1949) demonstrated the aetiological role of blind sacs in the production of megaloblastic anaemia. Though Montuschi (1949) had recorded the occurrence of steatorrhoea in a patient with many diverticula, it was left to Badenoch and Bedford (1954) to describe two patients with three major features, diverticula of the small intestine, megaloblastic anaemia, and steatorrhoea. In 1955 Badenoch, Bedford, and Evans added three further cases and noted that antibiotics improved the absorption of radioactive vitamin B12. This supported their opinion that there was a causal relationship between the diverticula and the deficiency of vitamin B12. Since that time many similar patients with diverticula have been described as well as some with only megaloblastic anaemia and others with only steatorrhoea (Table I).

Despite the fact that the case histories of recorded patients are remarkably similar with recurrent abdominal symptoms of varying intensity, the impression engendered by many writers is that, diverticula are not usually associated with symptoms and that uncommon complications-anaemia, haemorrhage, inflammation, and obstruction-are the only ones that cause distress. Lee and Finby (1958) sum up this view with the comment: 'In most cases, these diverticula are incidental findings detected radiographically, at operation, or on post-mortem examination. Many patients with diverticula have signs and symptoms but co-existing organic processes 
TABLE I

PATIENTS WITH JEJUNAL DIVERTICULA, MACROCYTIC ANAEMIA, AND STEATORRHOEA WITH ADEQUATE DATA RECORDED IN THE LITERATURE

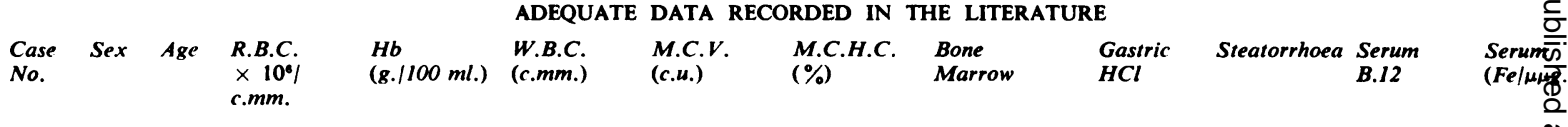

\begin{tabular}{|c|c|c|c|c|c|c|c|}
\hline 1 & $\mathbf{F}$ & 55 & 1.4 & 5.4 & - & 108 & 37 \\
\hline 2 & $\mathbf{M}$ & 66 & 4.00 & $11 \cdot 5$ & 6,400 & - & - \\
\hline 3 & $\mathbf{F}$ & 39 & - & 6.6 & - & - & - \\
\hline 4 & $\mathbf{M}$ & 58 & 3.84 & 11.9 & 5,200 & - & - \\
\hline 5 & $\mathbf{F}$ & 70 & $3 \cdot 15$ & $11 \cdot 7$ & - & - & - \\
\hline 6 & $\mathbf{F}$ & 79 & $2 \cdot 2$ & 8.9 & - & - & - \\
\hline 7 & $\mathbf{F}$ & 49 & $2 \cdot 3$ & 10.7 & 6,200 & - & - \\
\hline 8 & $\mathbf{M}$ & 52 & - & $14 \cdot 5$ & - & - & - \\
\hline 9 & $\mathbf{F}$ & 25 & $1 \cdot 15$ & $4 \cdot 9$ & 2,000 & - & - \\
\hline 10 & $\mathbf{F}$ & 79 & 4.00 & 14 & - & 112 & 31 \\
\hline 11 & $\mathbf{F}$ & 71 & $3 \cdot 81$ & 13.4 & - & 110 & 32 \\
\hline 12 & $\mathbf{F}$ & 70 & $1 \cdot 36$ & 5.9 & 2,500 & 143 & 30 \\
\hline 13 & $\mathbf{F}$ & 70 & $1 \cdot 50$ & 6.0 & 850 & 116 & 34 \\
\hline 14 & $\mathbf{M}$ & 68 & - & - & - & - & - \\
\hline 15 & $\mathbf{M}$ & 60 & 2.49 & $8 \cdot 0$ & - & 108 & 30 \\
\hline 16 & $\mathbf{F}$ & 59 & $2 \cdot 32$ & $8 \cdot 4$ & 4,250 & 112 & 32 \\
\hline 17 & $\mathbf{F}$ & 79 & $2 \cdot 32$ & 6.8 & - & 110 & 32 \\
\hline 18 & $\mathbf{F}$ & 80 & 2.96 & $10 \cdot 1$ & - & 117 & - \\
\hline 19 & $\mathbf{F}$ & 59 & $2 \cdot 4$ & $7 \cdot 2$ & - & 120 & 30 \\
\hline 20 & $\mathbf{M}$ & 59 & 2.65 & $12 \cdot 4$ & 5,200 & - & - \\
\hline 21 & $\mathbf{M}$ & 61 & 3.49 & 11.5 & 8,100 & - & - \\
\hline 22 & $\mathbf{M}$ & 70 & 1.9 & 5.5 & 2,100 & - & - \\
\hline 23 & $\mathbf{M}$ & 64 & 1.6 & 6.5 & 3,030 & 144 & $32 \cdot 5$ \\
\hline 24 & $\mathbf{M}$ & 61 & 5.25 & 14.0 & - & - & - \\
\hline 25 & $\mathbf{F}$ & 76 & $2 \cdot 35$ & $7 \cdot 6$ & 4,200 & 106 & 31 \\
\hline 26 & $\mathbf{F}$ & 45 & $2 \cdot 10$ & $6 \cdot 3$ & - & 100 & 30 \\
\hline 27 & $\mathbf{M}$ & 85 & $3 \cdot 10$ & $10 \cdot 3$ & 5,400 & 100 & 31 \\
\hline 23 & $\mathbf{M}$ & 64 & $2 \cdot 32$ & 8.4 & - & 112 & 32 \\
\hline 27 & $\mathbf{F}$ & 75 & 1.48 & $4 \cdot 7$ & - & 111 & 29 \\
\hline 30 & $\mathbf{M}$ & 76 & 3.00 & $9 \cdot 7$ & - & 98 & 31 \\
\hline 31 & $\mathbf{M}$ & 65 & $1 \cdot 32$ & 5.0 & 2,200 & 128 & 38 \\
\hline
\end{tabular}

A $=$ grossly impaired absorption as in pernicious anaemia

I = subnormal absorption but greater than that found in pernicious anaemia

\begin{tabular}{|c|c|c|c|}
\hline - & Present & - & - \\
\hline & Present & Present & - \\
\hline $\begin{array}{l}\text { Megaloblastic } \\
\text { Megaloblastic }\end{array}$ & Absent & $\overline{\text { Present }}$ & - \\
\hline Megaloblastic & Present & Present & - \\
\hline Megaloblastic & Absent & Present & - \\
\hline Megaloblastic & Present & Present & - \\
\hline & Absent & Present & - \\
\hline Megaloblastic & Present & Present & - \\
\hline & - & Present & - \\
\hline Megaloblastic & Present & Present & 一 \\
\hline Megaloblastic & Absent & Present & - \\
\hline Megaloblastic & Present & Present & - \\
\hline Megaloblastic & Absent & Present & - \\
\hline Megaloblastic & Present & Absent & - \\
\hline $\begin{array}{l}\text { Megaloblastic } \\
\text { Megaloblastic }\end{array}$ & Absent & Present & Low \\
\hline Megaloblastic & Absent & Absent & Low \\
\hline Megaloblastic & Present & Absent & Low \\
\hline Megaloblastic & Present & Absent & - \\
\hline S & Absent & Present & - \\
\hline Megaloblastic & Present & - & - \\
\hline Megaloblastic & Present & Abs. Pres. & Low \\
\hline & Present & Present & Low \\
\hline - & Present & Present & 一 \\
\hline Megaloblastic & Present & Absent & - \\
\hline Megaloblastic & Present & Present & - \\
\hline Megaloblastic & Present & Present & 一 \\
\hline- & Present & Present & 一 \\
\hline $\begin{array}{l}\text { Megaloblastic } \\
\text { Megaloblastic }\end{array}$ & $\begin{array}{l}\text { Absent } \\
\text { Absent }\end{array}$ & Present & Low \\
\hline
\end{tabular}

$\mathrm{N}=$ normal absorption of $\mathrm{CoB} 12$

or functional states are in most cases the cause of the complaints rather than the diverticula'. They considered that in only two of their $\mathbf{4 5}$ patients were the diverticula the cause of the patients' symptoms.

Our own experience is at variance with this view. In this paper we compare our observations on 33 patients with those reported elsewhere. Thirty were diagnosed during three consecutive years from amongst 2,400 radiological examinations of the small intestine but two of them were not available for investigation and so are not included. The remaining five patients (cases $1,2,6,30,33$ ) were referred from other hospitals to the nutritional and intestinal clinic.

\section{METHODS}

Detailed histories and clinical examinations were made on each patient. Complete haematological assessment was performed using routine procedures on sequestrenized blood. Serum vitamin B12 was determined microbiologically using $\boldsymbol{L}$. leichmanii (Meynell, Cooke, Cox, and Gaddie, 1957) with the addition of potassium cyanide to the extraction medium (Spray, 1955). The 58CoB12 absorption tests were performed using the hepatic uptake method (Fone, Cooke, Meynell, and Harris, 1961). Folic acid excretion tests were carried out by the method described by Cox, Meynell, Cooke, and Gaddie (1958) and d-xylose excretion by that described by Fowler and Cooke (1960). Faecal fat determinations were made by the method of van de Kamer (1949). Estimations of the serum proteins (Weichselbaum, 1946), calcium (Fowler, 1961), phosphorus (Fowler and Cooke, 1960), and phosphatase (King, Haslewood, Delory, and Beall, 1942) were also made. Jejunal biopsies were obtained with the Crosby capsule.

\section{CLINICAL MATERIAL}

SEX INCIDENCE Eleven patients were men and 22 women. Amongst the reported cases, the sex incidence is approximately equal. However, in some of the larger series, e.g., that of Lee and Finby (1958), and in those with a macrocytic anaemia (Table I), there are more women. 
TABLE I-continued

PATIENTS WITH JEJUNAL DIVERTICULA, MACROCYTIC ANAEMIA, AND STEATORRHOEA WITH ADEQUATE DATA RECORDED IN THE LITERATURE

CoB12 Absorption

Fac

Serum/100 ml.

\begin{tabular}{lllll}
\hline $\begin{array}{llll}\text { Albumin } \\
(\mathrm{g} .)\end{array}$ & $\begin{array}{l}\text { Globulin } \\
(\mathrm{g} .)\end{array}$ & $\begin{array}{l}\text { Ca } \\
(\mathrm{mg} .)\end{array}$ & $\begin{array}{l}\boldsymbol{P} \\
(\mathrm{mg} .)\end{array}$ & Authors
\end{tabular}

\begin{tabular}{|c|c|c|c|c|}
\hline - & - & - & - & Harvey and Murphy (1933) \\
\hline - & - & - & - & Montuschi (1949) \\
\hline$\overline{3.6}$ & $\overline{2}$ & $\overline{7.6}$ & $\overline{-2}$ & Spang (1954) \\
\hline - & $2 \cdot 3$ & $\begin{array}{l}7 \cdot 6 \\
-\end{array}$ & $2 \cdot 3$ & Badenoch and Bedford (1954) \\
\hline- & - & - & - & Badenoch, Bedford, and Evans (1955) \\
\hline $2 \cdot 9$ & $3 \cdot 0$ & $7 \cdot 4$ & - & \\
\hline$\overline{7.75}$ & $\overline{0}$ & - & - & \\
\hline $2 \cdot 75$ & $2 \cdot 55$ & 二 & - & Wilkinson (1955) \\
\hline 2.6 & 3.0 & $\overline{11 \cdot 1}$ & $\overline{2.8}$ & $\begin{array}{l}\text { Friedlander and Gorvy (1955) } \\
\text { Dick (1955) }\end{array}$ \\
\hline - & - & $9 \cdot 4$ & 4.6 & Blachford and Dawson (1956) \\
\hline - & - & - & - & Gellman (1956) \\
\hline$\overline{202}$ & $\overline{-1}$ & - & - & Welbourn, Nelson, and Zacharias (1956) \\
\hline 3.3 & $2 \cdot 1$ & - & - & Halsted, Gasster, and Lewis (1956) \\
\hline - & - & $\bar{x}$ & $\bar{x}$ & Krevans, Conley, and Sachs (1956) \\
\hline - & - & $\mathbf{N}$ & $\mathbf{N}$ & Townsend and Cameron (1957) \\
\hline$\overline{-}$ & $\overline{-}$ & $\mathbf{N}$ & $\begin{array}{l}\mathbf{N} \\
\mathbf{N}\end{array}$ & \\
\hline $\mathbf{N}$ & $\mathbf{N}$ & $\mathbf{N}$ & $\mathbf{N}$ & Scudamore, Hagedorn, Wollaeger, and Owen (1958) \\
\hline $2 \cdot 44$ & $2 \cdot 8$ & $8 \cdot 2$ & - & \\
\hline$\overline{2 \cdot 5}$ & $\overline{1.8}$ & $\overline{9 \cdot 1}$ & $\overline{3 \cdot 5}$ & $\begin{array}{l}\text { Lee and Finby (1958) } \\
\text { Watkinson. Feather Marson and Dossett (1959) }\end{array}$ \\
\hline - & - & - & - & $\begin{array}{l}\text { Watkınson, Feather, Marson, and Dossett (1959) } \\
\text { Doig and Girdwood (1960) }\end{array}$ \\
\hline $2 \cdot 6$ & 1.9 & 8.6 & 3.8 & Johnson and Wysor (1961) \\
\hline$\overline{4 \cdot 2}$ & $\overline{2 \cdot 1}$ & $\overline{8 \cdot 4}$ & $\overline{2 \cdot 5}$ & Crawford and Freeman (1961) \\
\hline $2 \cdot 4$ & 4.8 & - & - & Polachek, Pijanowski, and Miller (1961) \\
\hline $2 \cdot 0$ & $2 \cdot 8$ & - & - & \\
\hline $2 \cdot 2$ & 3.4 & - & - & \\
\hline $2 \cdot 5$ & $2 \cdot 6$ & $8 \cdot 2$ & $2 \cdot 9$ & Schiffer, Faloon, Chodos, and Lozner (1962) \\
\hline
\end{tabular}

AGE INCIDENCE The age at the time of diagnosis ranged from 20 to 83 years, though only four were below 50 . Three of these four younger patients were men. In other series, the age range was essentially the same, and though nearly all the patients were over the age of 50, young patients have been reported. Benson, Dixon, and Waugh (1943) described a child of 13 who had had symptoms for nine years and referred to others. Verster (1937) resected the affected area of the jejunum of a 21-year-old woman, with symptoms since the age of 8 . Megaloblastic anaemia and steatorrhoea were found in a woman of 25 by Wilkinson (1955). Kozinn and Jennings (1941) described jejunal diverticulitis in a 2-year-old child, but since it arose from the antimesenteric border, this was probably congenital in origin.

ASSOCIATED DISORDERS Case 5 had mild congestive cardiac failure, mitral stenosis, and later developed diabetes. Another patient (case 16) with mitral stenosis, auricular fibrillation, and pyrexia was admitted to hospital with a diagnosis of subacute bacterial endocarditis. Investigations revealed jejunal diverticulosis, steatorrhoea, and intestinal infection as the cause of her symptoms. Mild congestive failure due to coronary artery disease was present in two other patients. Nine patients had hiatus herniae. Two patients had incisional herniae, two had repairs of inguinal herniae, and two had severe prolapse. One patient (case 15) had had a partial gastrectomy. Welbourn, Nelson, and Zacharias (1956) have reported a similar patient.

\section{CLINICAL FEATURES}

As noted in other series, three patients (cases 13, 14, and 20) had symptoms referable to a primary disorder other than the associated jejunal diverticulosis. In one there was a carcinoma of the stomach, in another a duodenal ulcer with pyloric stenosis, and in the third carcinomatosis from an unknown site. In two of these, neither steatorrhoea nor impairment of absorption of vitamin B12 were found, and the third patient was too ill to warrant further investigation. These three patients have been 
TABLE II

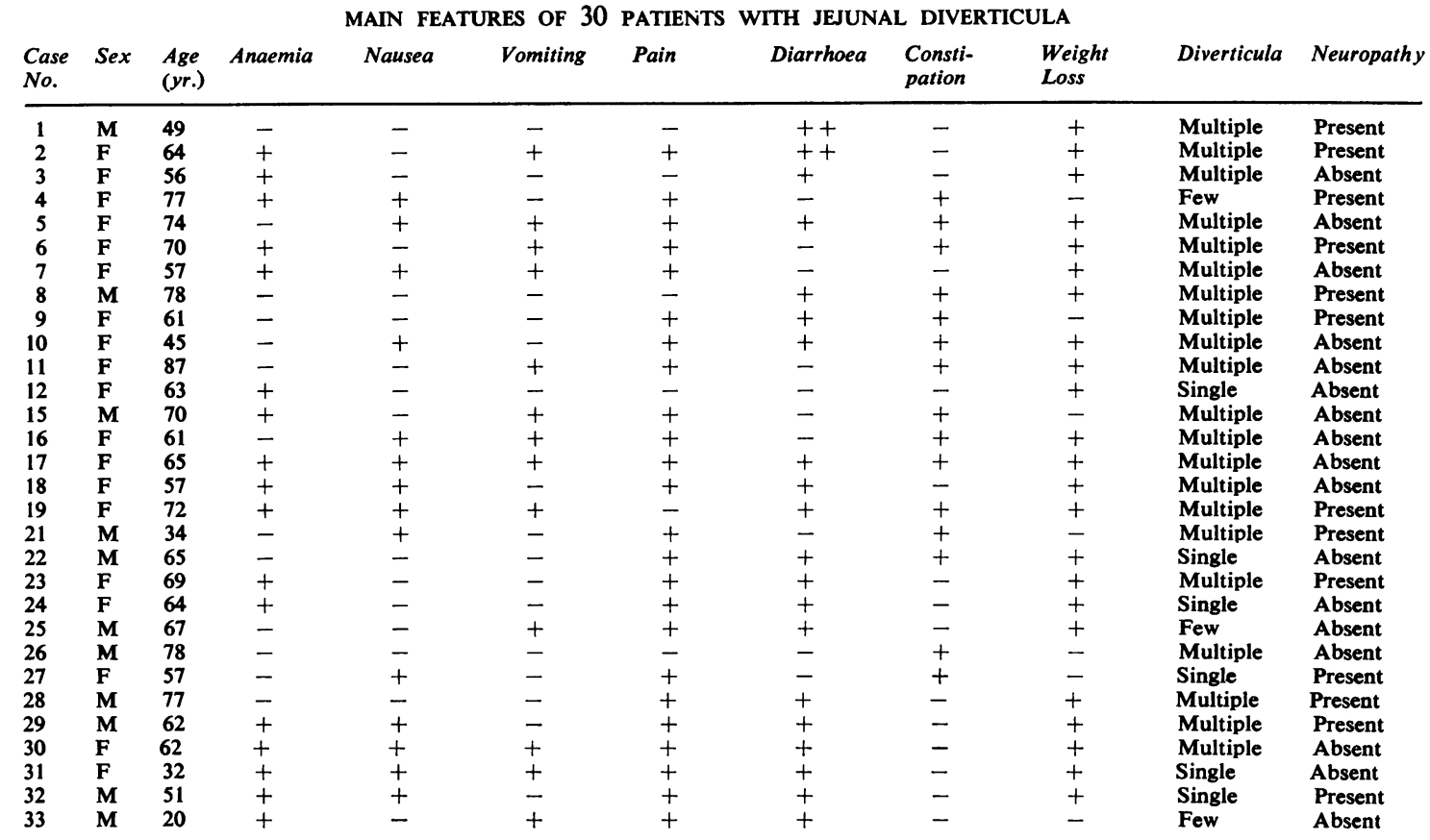

Cases 3. 14, and 20 are excluded because of associated intra-abdominal disease. $+=$ Present.

excluded from further discussion except when they are specifically referred to.

The main features of the remaining 30 patients are listed in Table II. Symptoms of alimentary disturbances were present in every patient except one whose only symptom was anorexia. The remainder had a fairly characteristic pattern of symptomsabdominal pain of varying severity, vomiting, constipation, diarrhoea, and abdominal distensionwith much variation during prolonged observation in individual patients.

Pain occurred in 23 patients and varied in character from a gnawing ache or burning pain to severe colic. It was always intermittent, lasting a few hours to days with intervals between the attacks, sometimes of many months. It was most frequently situated in the midline around the umbilicus, or in the epigastrium, or both; it radiated through to the back in a number of patients, and in a few to the lower abdomen. In seven patients it was made worse or improved by changes of posture. When pain was severe the onset was acute and usually occurred shortly after a large meal. Severe pain was associated with nausea in 12 patients, and in nine others with vomiting, which sometimes afforded a measure of relief. Mild abdominal discomfort and diarrhoea were common between the attacks of pain. In two patients recurrent attacks of colicky abdominal pain were associated with profuse watery stools up to 15 times a day. Though pain might only last for one or two days, diarrhoea often persisted for several days and the stools then might be large and pale.

In seven patients there was no abdominal pain, though all had disturbances in bowel habits; three had bouts of constipation and diarrhoea, three had bouts of diarrhoea alone, and one intermittent attacks of constipation. Profuse diarrhoea can readily give rise to electrolyte depletion and with the consequent progressive intestinal distension may precipitate volvulus. Case 2 was admitted on two occasions following diarrhoea with severe pain, abdominal distension, and vomiting. With rehydration and repletion of potassium, the condition settled. Volvulus complicating diverticulosis of the small intestine has been reported by Stiven (1934) and by Godard, Bourdial, and Zourekatis (1932).

PERFORATION Case 11 had a five-year history of abdominal discomfort, pain, and intermittent constipation. At the age of 86 she was admitted with signs of peritonitis. Laparotomy revealed that one of many jejunal diverticula had perforated. Following surgical repair, she made an excellent recovery and was well 18 months later. Spontaneous perforation 
has been reported on relatively few occasions (Shutkin, 1945) and occasionally occurs following trauma (Butler, 1937).

INTESTINAL HAEMORRHAGE Four patients (cases 2, 16,17 , and 24) had haematemeses. This was the presenting feature in cases 16 and 24, although on admission case 16 disclosed a nine-year history of attacks of epigastric pain, abdominal distension, and constipation, and during subsequent observation had bouts of diarrhoea; case 24 had a sixyear history of attacks of abdominal pain and diarrhoea; case 17 had haematemesis and melaena after diagnosis and had a seven-year history of intermittent attacks of epigastric pain, vomiting, abdominal distension and constipation, and she later developed bouts of diarrhoea. Case 2 had a severe haematemesis eight years after she had presented with neuropathy and a megaloblastic anaemia. Haemorrhage, either as haematemesis, melaena, or the passage of bright blood, has been reported by many authors (Braithwaite, 1923; Kozoll, McMahon, and Kiely, 1950; Orr and Russell, 1951; Waterson, 1952; Warthen, 1953; Denkewalter, Molnar, and Horava, 1958; McCollum, 1959; Silen, Brown, Orloff, and Watkins, 1960; Delaney and Hedges, 1962). Two patients (cases 10 and 23) had an associated proctitis with troublesome diarrhoea, which lead to the tentative initial diagnosis of ulcerative colitis. However, in neither case was there evidence of any organic disease of the large intestine on sigmoidoscopy or $x$-ray examination.

WEIGHT Loss Weight loss was a common associated complaint. It was more than $7 \mathrm{lb}$. in 24 of the 30 patients and in one case was as much as $34 \mathrm{lb}$. Weight, however, was subject to fluctuation, the losses coinciding with exacerbation of the patients' symptoms. For example, case 16 lost $14 \mathrm{lb}$. in four weeks between observations at a time when she had a severe exacerbation of her symptoms with diarrhoea and melaena, whereas case 28 gained $28 \mathrm{lb}$. in three months following relief of her symptoms with antibiotic therapy.

NEUROLOGICAL SYMPTOMS These were present in 12 of this group of patients. In five they caused the patient to seek advice. Case 2 became bedridden with severe anaemia and progressive paraplegia within three months of developing diarrhoea. Case 1, though initially diagnosed at laparotomy at the age of 25 , came under hospital observation for the second time 24 years later on account of numbness, weakness of the legs, and ataxia. Case 21 presented with numbness and lightning pains in the legs for which he consulted a neurologist. Case 27 developed severe peripheral neuritis and foot drop. Case 19 had been under treatment for 'pernicious anaemia' but developed progressive unsteadiness of gait which led to more detailed investigation and correction of the diagnosis. Subacute combined degeneration of the cord has been recorded in other patients with intestinal diverticulosis (Harvey and Murphy, 1933; Wilkinson, 1955; Krevans, Conley, and Sachs, 1956) although in the case described by Wilkinson there was also an ileocolic fistula caused by one of the diverticula. Peripheral neuropathy has been reported by Badenoch, Bedford, and Evans (1955), Blachford and Dawson (1956), Gellman (1956), Townsend and Cameron (1957), and Scudamore, Hagedorn, Wollaeger, and Owen (1958).

ANAEMIA Apart from case 2, who was first seen with severe neurological symptoms and a megaloblastic anaemia, symptoms attributable to anaemia were the most important feature in only two other patients. Case 6 presented with a megaloblastic anaemia and a haemoglobin of $20 \%$, which responded to vitamin $\mathrm{B} 12$ but because of unsatisfactory progress was referred to us eight months later. Case 15 had a severe microcytic anaemia due to iron deficiency, which was more probably due to a previous partial gastrectomy. It was difficult, however, to assess the contribution to symptoms made by moderate degrees of anaemia in the other patients who also had diarrhoea and had lost weight, and in three patients who had mild congestive failure.

\section{PHYSICAL FINDINGS}

PHYSICAL APPEARANCE Two patients (cases 2 and 12) had severe kyphoscoliosis and 12 patients were obese even though eight of these had lost weight. Eight of the obese females had a surprisingly similar appearance, broad and thick set, fat in the face and neck, high bosom with a protruding barrelshaped abdomen, accentuated by lumbar lordosis and large buttocks.

The findings on examination of the abdomen varied according to the severity of the complications. Visible peristalsis, loud borborygmi, and increased bowel sounds suggestive of intestinal obstruction were observed in the patients with more severe abdominal symptoms. Localized tenderness in the upper abdomen and ill-defined masses were recorded. Distension of varying degree was common.

NEUROLOGICAL FINDINGS The findings in the 12 patients varied and included disorders of lateral and posterior columns and peripheral neuritis. These complications are discussed in greater detail later. 


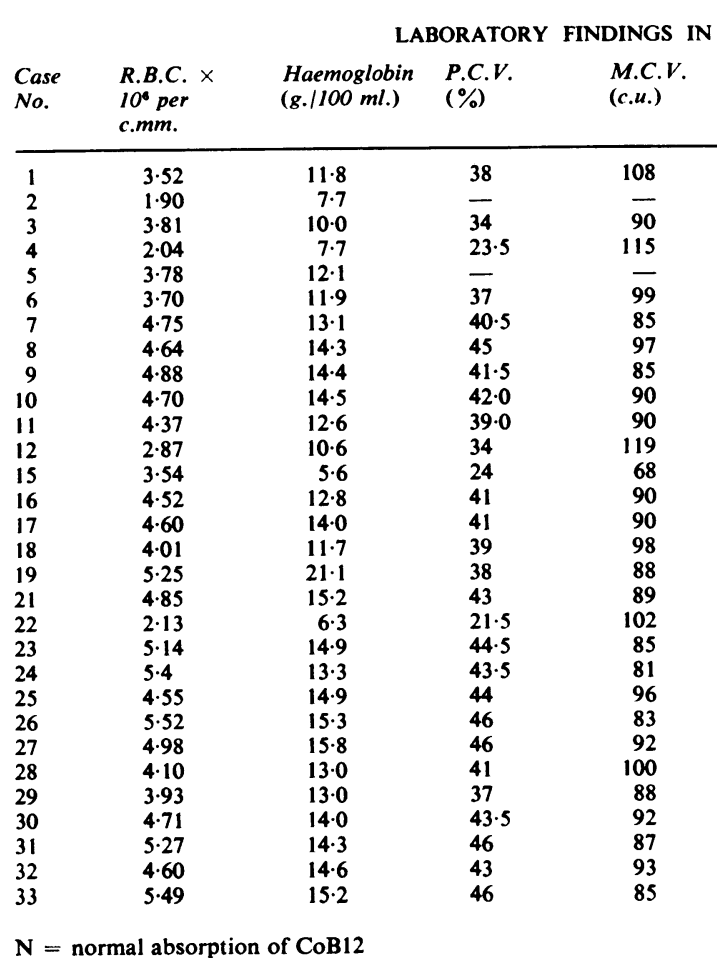

\section{LABORATORY FINDINGS}

The main haematological and laboratory findings are given in Table III.

GASTRIC ACIDITY Gastric $\mathrm{HCl}$ was present on maximal stimulation in 23 of the 30 patients in whom it was tested. Gastric biopsies from five of the seven patients with histamine-fast achlorhydria showed atrophy in each. In the six patients with free acid, five had virtually normal gastric biopsies, but one (case 22) showed atrophy. Badenoch, Bedford, and Evans (1955) found gastric atrophy in two patients with achlorhydria and a normal biopsy in the one in whom gastric $\mathrm{HCl}$ was present. In the patients with free $\mathrm{HCl}$ reported by Watkinson, Feather, Marson, and Dossett (1959) and by Crawford and Freeman (1961) the gastric mucosa was normal. Gastric atrophy, despite the presence of free acid, was found in the patient with megaloblastic anaemia reported by Johnson and Wysor (1961).

JEJUNAL BIOPSIES These were performed in nine of our patients, including four with a megaloblastic anaemia, three of whom had steatorrhoea. Apart
TABLE III

30 Patients With JeJunal diverticula $\begin{array}{lllll}\text { M.C.H.C. } & \text { Gastric } & \text { Marrow } & \text { Serum } & \text { Fe }(\mu g . \\ (\%) & \text { Acid } & & B 12(\mathrm{m \mu g.}) & 100 \mathrm{ml} .)\end{array}$

$\begin{array}{lllr}31 & \text { Present } & \text { Megalobastic } & 135 \\ \overline{29} .5 & \text { Present } & \text { Megaloblastic } & -\overline{150}\end{array}$

$\frac{34}{32 \cdot 5} \quad$ Pre

\section{$32 \cdot 5$}

32

33

32

31
23.5

$23 \cdot 5$
$31 \cdot 5$

$34 \cdot 5$

30

32
35

35
$29 \cdot 5$

$33 \cdot 5$

30
34

34
34
$34 \cdot 5$

$34 \cdot 5$

32

34.5

$32 \cdot 5$

32
34

33

\section{Present}

Absent

Absent

Absent

Present

Absent

Absent

Present

Present

Present

Present

Absent

Present

Present

Absent

Present

Present

Present

Absent

Present

Present

Present

Present

Present

Present

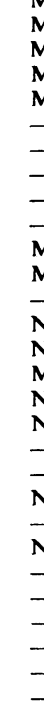

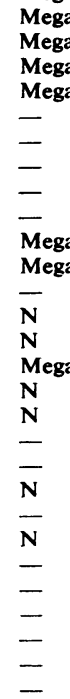

150

135

85

$2 \overline{10}$

190

190

100

190

100

100
100
195

195
385

385
210

500

500
205

315

500

200
315

400
60

60
110
500

200

220

225

167

from some cellular infiltration and some oedema, they were normal in every case.

HAEMATOLOGY Ten patients had red cell counts below $4.0 \mathrm{~m}$. per c.mm. and 12 had haemoglobin levels of less than $12.8 \mathrm{~g}$. per $100 \mathrm{ml}$. At the time of diagnosis, five patients (cases 1, 2, 4, 5, and 12) had a megaloblastic anaemia. Two other patients (cases 6 and 19) before diagnosis had been successfully treated with vitamin B12 for a megaloblastic anaemia. Similarly, case 23 had had a macrocytic anaemia which had been observed to respond satisfactorily to refined liver extract initially and the patient was subsequently maintained on vitamin B12. Case 15 had a severe microcytic anaemia following partial gastrectomy, but after showing a response to iron and then antibiotics, his blood count fell, becoming macrocytic, and the bone marrow showed evidence of megaloblastic erythropoiesis (Fig. 1). Case 3, who initially presented with a mild hypochromic anaemia, in spite of four courses of antibiotics during the following year, developed a megaloblastic anaemia. Thus 10 patients had a proven or probable megaloblastic anaemia at some time. 

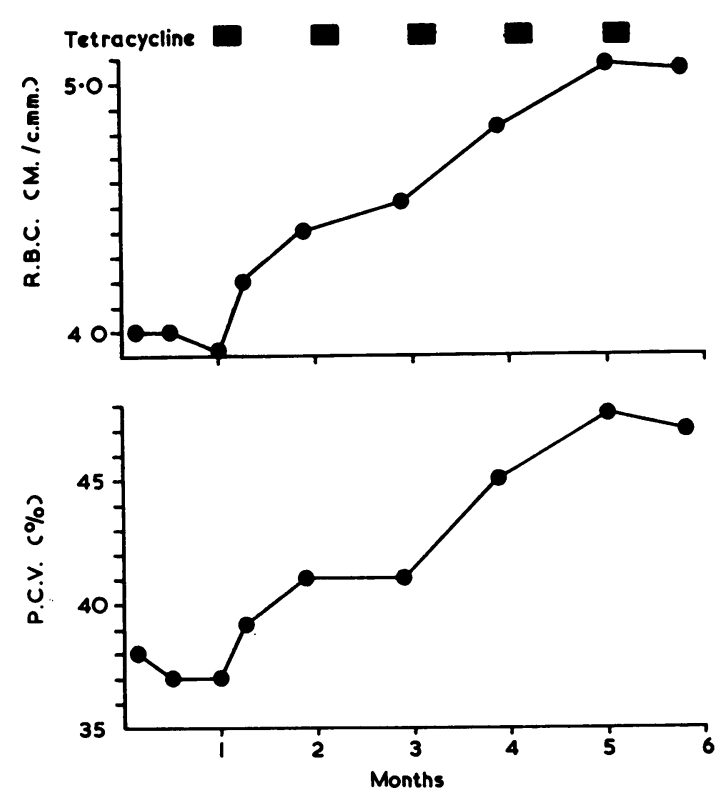

FIG. 2. The haematological response following intermittent antibiotic therapy in case 29. The serum levels of iron, B12, and folic acid were normal before treatment.

Even with adequate therapy with vitamin B12, case 6 still had a mild macrocytic anaemia and this, like the normocytic anaemia in case 29 , returned to normal with antibiotic therapy (Fig. 2).

Case 22, with scurvy, a hypochromic anaemia $(\mathrm{Hb}=6.3 \mathrm{~g} . \%)$ and normoblastic erythropoiesis while on a scorbutogenic diet, responded to vitamin C though folic acid was eventually necessary to

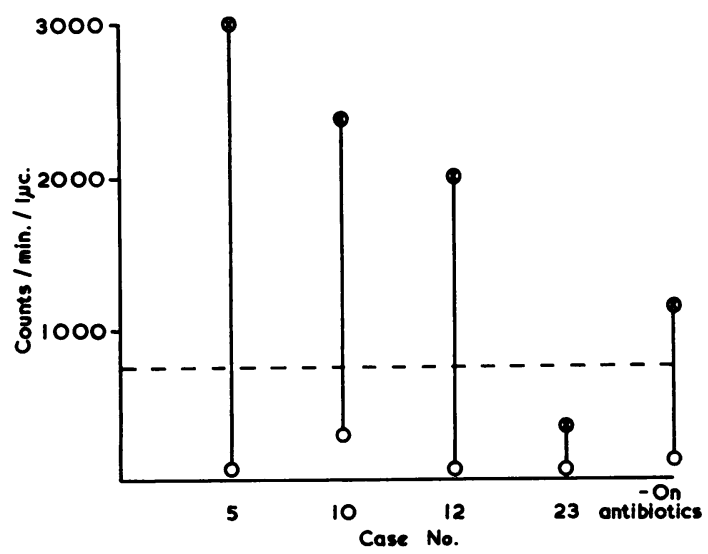

FIG. 3. The effect of intrinsic factor on the hepatic uptake of $58 \mathrm{CoB} 12$.

$\mathrm{O}=\mathrm{B} 12$

$\oplus=B 12+$ intrinsic factor obtain a full haematological remission. The only other patient with severe anaemia $(\mathrm{Hb}=3.0 \mathrm{~g} . \%$, $)$ was case 24 as the result of haematemesis. The blood picture shown in Table III is that three months later after blood transfusion and oral iron therapy.

VITAMIN B12 DEFICIENCY Nine patients (cases 1, 4, $5,10,12,15,27,28$, and 32 ) had subnormal serum vitamin B12 levels when they presented. Case 3 subsequently developed low serum vitamin B12 levels. Four other patients (cases 2, 6, 19, and 23) had shown earlier a haematological response to vitamin B12 or refined liver extract. Thus in all, 14 patients had evidence of vitamin B12 depletion.

ABSORPTION OF RADIOACTIVE VITAMIN B12 (58CoB12) The hepatic uptake of $58 \mathrm{CoB} 12$ was determined in 29 patients following its oral administration (Table III). In nine patients (cases 1, 2, 3, 5, 10, 12, 18, 19, and 23) this was as low as that observed in pernicious anaemia. Three of these patients (cases 5, 10, and 12) absorbed $58 \mathrm{CoB} 12$ normally when intrinsic factor was administered simultaneously, thus resembling the findings in pernicious anaemia (Fig. 3). Case 23 required the simultaneous administration of both intrinsic factor and antibiotics to achieve her maximum hepatic uptake, which still fell below the normal range (Fig. 3). The remaining five patients (cases 1, 2, 3, 18, and 19) absorbed 58CoB12 normally when the test dose was given on the fourth day of a seven-day course of either tetracycline, aureomycin, or erythromycin ( $250 \mathrm{mg}$. q.d.s.).

Five other patients (cases 4, 15, 16, 24, and 27) had a $58 \mathrm{CoB} 12$ absorption level below the normal range and yet above that found in pernicious anaemia. Intrinsic factor produced no improvement in three of these patients (cases 15, 16, and 27); after receiving antibiotics, four (cases $4,15,16$, and 27) had normal absorption. Absorption was also normal in case 24 following the resection of a solitary jejunal diverticulum. Three patients (cases 19, 21, and 27) before the administration of antibiotics were examined when $58 \mathrm{CoB} 12$ was given with $10 \mathrm{~g}$. sodium bicarbonate. All showed significant improvement in absorption, though one patient (case 19) vomited on both occasions within 20 minutes of the administration of the $58 \mathrm{CoB} 12$ and sodium bicarbonate (Fig. 5). Cases 4 and 6, with megaloblastic anaemia due to $\mathrm{B} 12$ deficiency, and cases 28 and 32 with subnormal serum B12 levels, all had normal absorption of $58 \mathrm{CoB} 12$, anomalies which could be attributed to antibiotic therapy given before admission. To summarize, 10 patients with abnormal $58 \mathrm{CoB} 12$ absorption had evidence of vitamin B12 deficiency, or were already receiving vitamin B12 therapy for a previously diagnosed deficiency. 


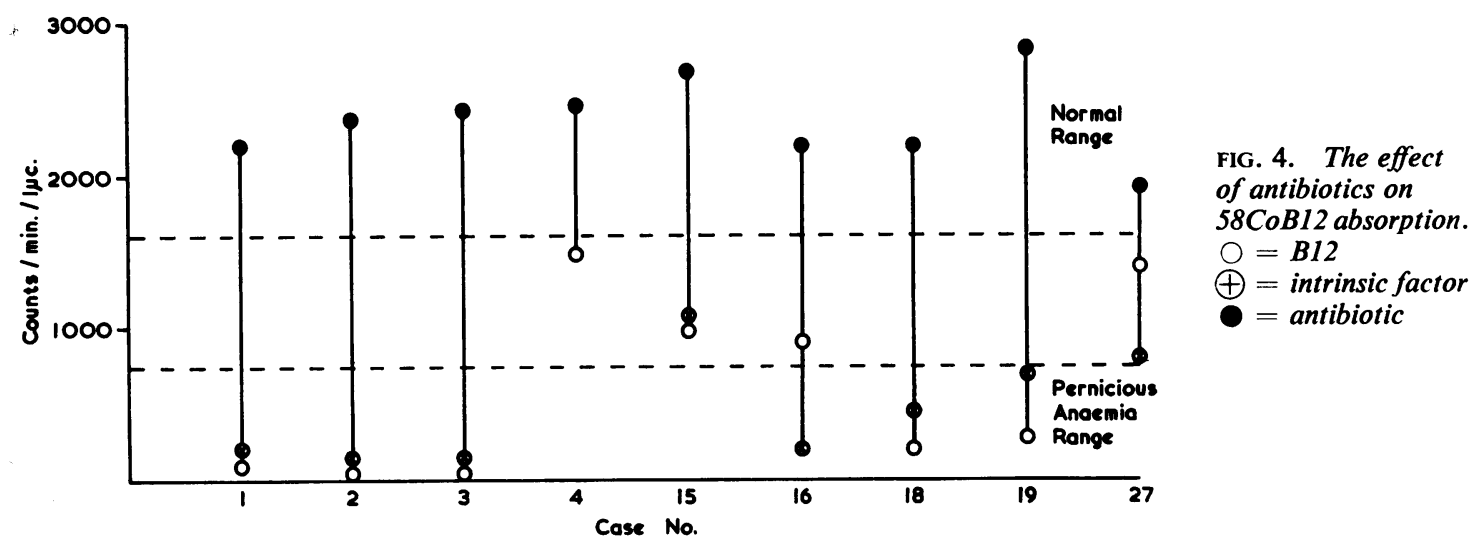

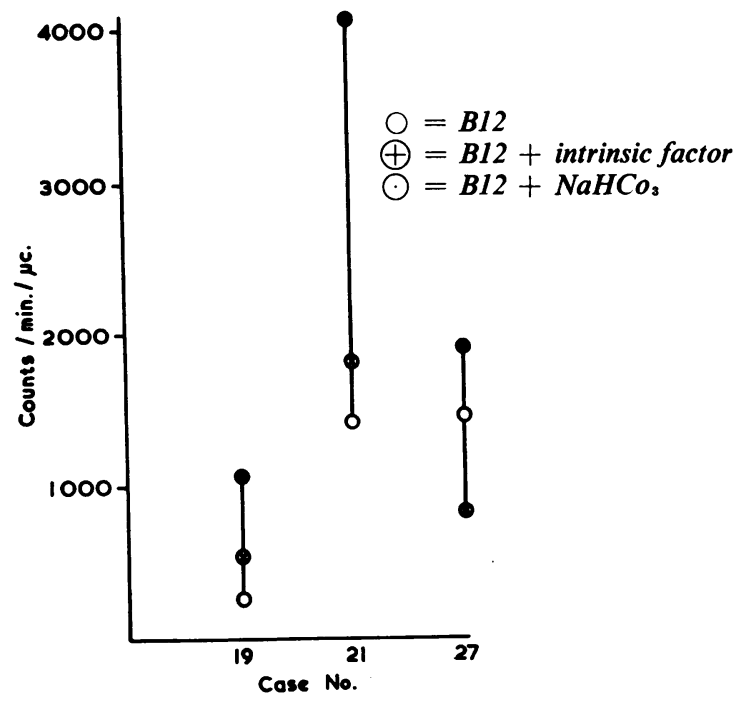

FIG. 5. The effect of the simultaneous administration of $58 \mathrm{CoB} 12$ and $10 \mathrm{~g}$. $\mathrm{NaHCO}_{3}$ in $100 \mathrm{ml}$. water on the absorption of $58 \mathrm{CoB} 12$.

FOLIC ACID The serum folic acid activity determined with Lactobacillus casei before therapy was below the normal range (3.0 to $15 \mathrm{mg}$. per $\mathrm{ml}$.) in two out of 16 patients (cases 18 and 22). Case 22 had scurvy so that the low level of folic acid could have been of dietary origin.

Folic acid excretion tests were done on 21 patients and the results were abnormal in six. The test was repeated after the administration of antibiotics for seven days and in each case the result was within the normal range (Fig. 6). Case 4 required folic acid in addition to vitamin B12 and case 22 in addition to vitamin $\mathrm{C}$ to achieve complete haematological remission. In case 4 the urinary excretion after $5 \mathrm{mg}$.

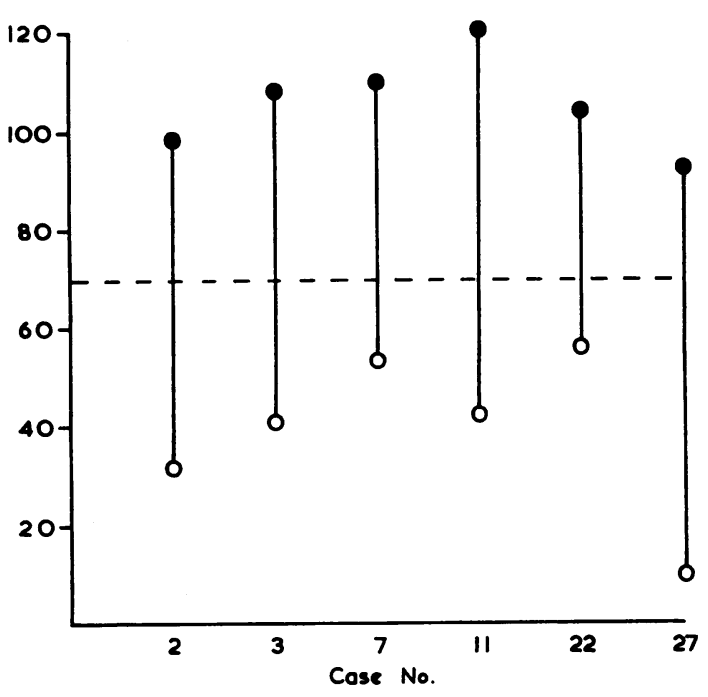

FIG. 6. The effect of antibiotics on the folic acid excretion test in six patients initially found to have abnormal tests. $\mathrm{O}=$ before antibiotics $\mathrm{O}=$ after antibiotics

folic acid intramuscularly was less than $1.6 \mathrm{mg}$. and so invalidated the excretion index given in Table III. The beneficial effects of folic acid therapy have been reported by Badenoch, Bedford, and Evans (1955), by Gellman (1956), by Welbourn, Nelson, and Zacharias (1956), and by Doig and Girdwood (1960).

IRON Only one patient (case 15) showed significant evidence of iron deficiency with a serum iron level of $8 \mu \mathrm{g}$. per $100 \mathrm{ml}$., but as stated earlier, he had also had a partial gastrectomy. Though four patients had haematemeses and melaena and two bloody diarrhoea, none developed any significant degree of iron-deficiency anaemia. Normal levels were re- 
ported by Townsend and Cameron (1957) and a low value was found by Wilkinson (1955).

SERUM PROTEINS The serum albumin was less than $4.1 \mathrm{mg}$. per $100 \mathrm{ml}$. in 20 of the 29 patients in whom it was determined. Nine of these were $3.5 \mathrm{mg}$. or less, the lowest being $1.8 \mathrm{mg}$. per $100 \mathrm{ml}$. Thirteen patients with low serum albumin levels had malabsorption of either folic acid or Co58B12. Eight had steatorrhoea. Antibiotic therapy resulted in improvement of these values. Only two of the 14 patients reported by the authors in Table I had normal levels of serum albumin.

CARBOHYDRATE METABOLISM Fifteen of the 18 patients who had glucose tolerance tests performed had normal results. Two (cases 4 and 5) had diabetic curves, and one patient (case 33) had a flat glucose tolerance curve. Of the patients recorded in Table I, glucose tolerance tests were normal in the eight patients tested.

D-xylose excretion tests were carried out in nine patients under the age of 65 years. Six patients, all with other evidence of malabsorption, excreted less than $4.2 \mathrm{~g}$., the lower limit of the normal range, in five hours after $25 \mathrm{~g}$. d-xylose by mouth. Three patients were re-tested after a course of antibiotics and showed normal excretion of d-xylose. Low excretion values of $d$-xylose have been reported by Watkinson, Feather, Marson, and Dossett (1959), by Johnson and Wysor (1961), and by Schiffer, Faloon, Chodos, and Lozner (1962).

CALCIUM, PHOSPHORUS, AND ALKALINE PHOSPHATASE Seven patients had serum calcium levels of less than $9.4 \mathrm{mg}$. per $100 \mathrm{ml}$. The serum phosphorus level was less than $2.6 \mathrm{mg}$. in two patients, whereas the alkaline phosphatase level was greater than 12 KingArmstrong units in 10. Two patients (cases 1 and 7) had the clinical features and radiological evidence of osteomalacia. Seven of the 12 patients reported in the literature (Table I) had serum calcium values of less than $9 \cdot 2 \mathrm{mg}$. per $100 \mathrm{ml}$.

FAECAL FAT EXCRETION Average daily faecal fat excretion was greater than $6 \mathrm{~g}$. in nine of the 27 patients in whom this determination was made. This finding probably underestimates the incidence of steatorrhoea, since many patients with a history of diarrhoea and the presence of pale bulky stools became constipated in hospital and had no steatorrhoea. There was no constant correlation between the presence of steatorrhoea and other evidences of malabsorption. Thus, while five patients had impaired absorption of both fat and 58CoB12, four patients had steatorrhoea and normal $58 \mathrm{CoB} 12$ absorption, and six patients had impaired $58 \mathrm{CoB} 12$ absorption (not due to a lack of intrinsic factor) and a normal fat excretion. Indeed, only four of 10 patients in whom antibiotics restored $58 \mathrm{CoB} 12$ absorption to normal had steatorrhoea. Similarly, only three out of the six patients with abnormal folic acid excretion tests had steatorrhoea.

The faecal fat excretion in three patients (cases 2 , 6 , and 27) with steatorrhoea was considerably improved by the administration of antibiotics. The effect of antibiotics on the faecal fats was studied in only three patients.

NEUROLOGY The high incidence of neurological symptoms and signs was a striking feature in this series. Twelve patients had neurological disturbance of sufficient severity to indicate a neuropathy or a neuromyelopathy. Four of these patients had subacute combined degeneration of the cord with objective signs of both posterior and lateral column disease and of peripheral neuritis. The serum B12 level was subnormal in the two patients tested and in each patient absorption of $58 \mathrm{CoB} 12$ was impaired and all showed haematological and neurological improvement following B12 therapy. Case 5 had objective signs of posterior column disturbance and absent ankle jerks but no pyramidal tract abnormality. She had a low serum level of vitamin B12 and malabsorption of $58 \mathrm{CoB} 12$ and improvement followed and was sustained by therapy with vitamin B12.

Five other patients had objective evidence of a peripheral neuropathy and posterior column disease confined to the lower limbs. Each of these patients complained of paraesthesiae in the feet, and had reduced or absent ankle jerks, rhombergism, a wide-based gait, and slight blunting of peripheral sensation. With vitamin B12 therapy two patients obtained no benefit and three after some initial improvement subsequently deteriorated despite adequate therapy with vitamin B12. Further improvement was obtained by intermittent or continuous antibiotic therapy, though the neurological disturbance fluctuated and disability persisted in three patients.

Two patients (cases 21 and 32) complained of severe paraesthesiae in the feet and legs, lightning pains around the ankles, and heaviness of the legs, but neither had any significant objective signs. Both patients had normal serum B12 levels; the B12 absorption was normal in one and borderline in the other and neither showed any improvement after the weekly injection of $1,000 \mu \mathrm{g}$. hydroxocobalamin for 12 weeks. These symptoms disappeared within four weeks of a 10-day course of tetracycline $(250 \mathrm{mg}$. q.d.s. in both instances), and there has been no 
evidence of a recurrence in the 12 and 14 months respectively following the commencement of antibiotic therapy. Both patients continue to take antibiotics intermittently.

Case 1 is the twelfth patient with a neurological disturbance. At the age of 26 this patient had a resection of the upper intestine containing numerous diverticula, after which he was symptom free until the age of 48 , when he had a recurrence of diarrhoea, abdominal swelling, and progressive weakness of the legs. These symptoms improved with treatment, including antibiotics but not vitamin B12, on admission to another hospital. They had recurred when admitted to the General Hospital for further investigation one year later. At that time, he had auricular fibrillation, congestive heart failure, severe oedema, absent tendon jerks, evidence of posterior column involvement in the legs, and an equivocal plantar response on the left. He died suddenly 10 days after the start of treatment with antibiotics, seven days after B12 therapy, and 14 days after multiple vitamin therapy (Parenterovite) at a time when he appeared to be improving.

\section{DIAGNOSIS}

The diagnosis of jejunal diverticula can only be made with certainty during life by radiological examination or laparotomy, though it may be suspected in an elderly patient with variable intestinal complaints, particularly when associated with megaloblastic anaemia. The incidence at necropsy varies from $0.3 \%$ reported by Edwards (1939) to $4.6 \%$ found by Noer (1960) on distending the bowel with air at necropsy. The reported incidence of jejunal diverticula by intestinal radiography is variable: Case (1920) reported 0.0006\%, Rankin and Martin (1934) $0.30 \%$, and Spriggs and Marxer (1925) $1.4 \%$. Twenty-eight of our patients were detected during a period of three years and two others were also diagnosed during this period, amongst 2,400 intestinal radiographs, giving an incidence of $1.25 \%$.

In this series, the diagnosis was made at operation in two (cases 1 and 11) and the remainder by radiological examination. The frequency of the diagnosis depends upon the awareness and skill of the radiologists. The use of a non-flocculating barium (e.g., Raybar), as pointed out by Johnson and Wysor (1961), is essential. A flocculating contrast medium will cause the condition to be overlooked unless there is retention of barium within the diverticula. Badenoch, Bedford, and Evans (1955) have also commented upon the difficulties that may be encountered with radiography: sacs with small openings may not always fill with barium and small diverticula may be difficult to differentiate from adjacent loops of small intestine. Plain radiographs of the abdomen with the patient in an upright position may occasionally be diagnostic, or mimic intestinal obstruction, as pointed out by Butler in 1933, and stressed by Philips (1953), Strömme (1956), and Johnson and Wysor (1961).

The diverticula in our patients varied considerably in number and size. Twenty-one had numerous diverticula but in 10 patients there were demonstrated only a single or few sacs. The upper jejunum was the major site of involvement, though in several patients some diverticula were present in the lower jejunum and two patients had ilial diverticula. The three patients in whom the diverticula were considered to be incidental had a few small sacs, which in one patient were confined to the ileum.

There was no consistent correlation between the number and size of the diverticula and the abdominal symptoms and absorptive disturbances. Thus, five of the six with steatorrhoea and macrocytic anaemia had massive diverticulosis of the jejunum, but the sixth (case 4) had only a few small sacs which were poorly defined. Two patients without anaemia or steatorrhoea had massive involvement; three similar patients had only a few or several small sacs. Scudamore, Hagedorn, Wollaeger, and Owen (1958) noted in their patients that the two with macrocytic anaemia had larger and more diverticula than the three without anaemia. In 10 patients of the present series there was also a single large diverticulum in the duodenum, situated in the second part in eight patients and in the third part in two. One patient (case 2) also had a single gastric diverticulum on the lesser curve. Diverticulosis of the large bowel was present in four patients. Lee and Finby (1958) found colonic diverticula in 24 of their 45 patients with small intestinal diverticulosis.

\section{PROGRESS AND TREATMENT}

A characteristic feature of this condition is the intermittent nature and the variable periodicity and severity of the symptoms extending over many years. In our patients the duration of symptoms up to the present time or death varied from 10 months to 24 years with a mean of seven years and four months.

Five patients have died (cases 1, 2, 5, 13, and 20), including the two patients with an associated neoplasm who have been excluded from the clinical assessment. Two patients (cases 1 and 2) survived 24 and 14 years after diagnosis and both had massive diverticulosis. Case 1 had a recurrence of symptoms 22 years after an initial resection and at the time of death, when aged 49 years, had gross oedema, severe diarrhoea with steatorrhoea, macrocytic anaemia, osteomalacia, probable beriberi, and cardiac failure. 
Case 2 died 14 years after the onset of symptoms, at the age of 78, having had numerous periods of nutritional upsets with steatorrhoea, macrocytic anaemia, abdominal and neurological disturbances. This patient died at home and no necropsy was obtained. Case 5 also died at home of heart failure, aged 78 years, four years after the onset of symptoms.

The remaining patients have been maintained in moderate or good health with replacement therapy, antibiotics, or surgical intervention. The therapy included vitamin B12, folic acid, iron, calciferol, and oral potassium. Potassium was administered as routine to patients with diarrhoea, but its efficacy is difficult to evaluate, though an obvious necessity in states of electrolyte and water depletion. Vitamin B12 was given parenterally whenever the level of serum B12 was low or the absorption of $58 \mathrm{CoB} 12$ defective, as has already been noted. Whenever B12 therapy was begun, it was found advisable to continue it indefinitely even though in four patients it was possible to restore the absorption of $58 \mathrm{CoB} 12$ to the normal range. Thus case 15 , who initially presented with iron deficiency which responded to oral iron, attained the normal ability to absorb $58 \mathrm{CoB} 12$, together with a short period of normal serum levels of B12, with frequent short courses of antibiotics. However, the serum level subsequently fell and he developed a macrocytic megaloblastic anaemia, which responded to parenteral vitamin B12 therapy (see Fig. 1).

Oral iron therapy was given to five patients (cases 15, 17, 18, 19, and 25). It corrected the anaemia in the patient just discussed (case 15) but was without apparent benefit in two patients (cases 18 and 19) who subsequent to diagnosis had developed low serum iron levels. These low levels were thought to be due to infection rather than to bleeding, since the total iron-binding capacity of the serum remained within normal limits. The remaining two patients received therapy following haematemesis and melaena.

As noted already, folic acid therapy completed the haematological response in two patients, but apart from the performance of folic acid excretion tests, was not administered to any other patient. The test doses (5 mg. on two separate occasions) did not produce any haematological response during the three weeks following their administration.

Calciferol was administered to one patient who had biochemical evidence of osteomalacia with complete relief of bone pains. It should be stressed that the need for replacement therapy was always assessed before the administration of antibiotics.

Apart from the beneficial effects on the absorption of vitamin B12, folic acid, and d-xylose, antibiotics were also found to produce considerable sympto- matic relief. Case 3 has remained virtually symptom free for 36 months following four seven-day courses of tetracycline during her first year under observation. Case 25 has been symptom free for 10 months following a single course of tetracycline. Tetracycline was without effect in two patients (cases 18 and 28). They were, however, restored to good health with erythromycin. In the one case, intermittent courses and, in the other, the continuous administration of tetracycline was necessary subsequently to maintain their remission. Nine patients (cases 7, 10, 15, 22, 27, 29, 30, 31, and 32) were found to be better when taking tetracycline or aureomycin, $250 \mathrm{mg}$. three or four times a day, for the first five or seven days of each month or whenever symptoms re-appeared. This therapeutic régime produced improvement in four other patients (cases 16, 19, 21, and 23) but their symptoms were of such severity that continuous therapy with tetracycline or aureomycin, $250 \mathrm{mg}$. twice daily, was begun. This produced further improvement which has been maintained for periods of observation ranging from five to 12 months. In the remaining eight patients, though antibiotics produced initial symptomatic improvement, the continued review has been unsatisfactory or too short to draw any satisfactory conclusion as to the effect of therapy. Finally, as has already been noted, antibiotic therapy, either continuous or intermittent, brought about complete amelioration of neurological symptoms in four patients and in three others the symptoms and physical signs either improved or showed no further deterioration.

SURGICAL INTERVENTION Two patients have benefited from surgical intervention, though both had shown previously symptomatic improvement with antibiotics. While on this therapy case 17 had a severe haematemesis necessitating the removal of a large duodenal diverticulum which stopped the bleeding though there were also several small jejunal diverticula which were left in situ. Histological examination showed that the mucosa of the diverticulum had multiple erosions. After the operation she continued to have attacks of diarrhoea and abdominal discomfort which were then adequately controlled by intermittent antibiotic therapy. Case 24 , who initially presented with a haematemesis and continued to have bouts of abdominal pain and diarrhoea, had a large solitary jejunal diverticulum removed with symptomatic relief. Case 1 , at the age of 26, had 117 in. of small intestine removed containing many diverticula, apparently all that were present at that time. He worked regularly for 22 years before developing severe symptoms of diarrhoea, anaemia, and neuropathy. At necropsy, the 
small intestine was grossly dilated with more than a hundred large diverticula, the largest being approximately $3 \mathrm{in}$. in diameter. Whether the resection of such a long length of bowel in a young person was beneficial is debatable. In the case reported by Polachek, Pijanowski, and Miller (1961) resection of the area of small intestine, which apparently contained all the visible diverticula at that time and was symptomatically beneficial, did not prevent the further development of a large number of diverticula found at necropsy 18 months later. Case 11, a woman aged 85, remained in good health following the resection of a perforated diverticulum and intermittent courses of antibiotics for 18 months when follow-up was discontinued.

Resections of diverticula have been reported also in five patients with steatorrhoea and macrocytic anaemia. One showed no improvement in the absorption of fat or vitamin B12 after resection of $45 \mathrm{~cm}$. of involved jejunum (Scudamore, Hagedorn, Wollaeger, and Owen, 1958) whereas the cases described by Watkinson, Feather, Marson, and Dossett (1959), Doig and Girdwood (1960), and Polachek, Pijanowski, and Miller (1961) after the resection of 70,73, and $160 \mathrm{~cm}$. of jejunum had normal or improved fat and B12 absorption. It has also been performed by a number of other surgeons with good results (Braithwaite 1923; Wilkerson and Coffman 1948; Orr and Russell, 1951; and Phillips, 1953), though no metabolic investigations were carried out in these cases.

\section{DISCUSSION}

Jejunal diverticula are herniations of mucosa through the submucosa and muscularis on the mesenteric side of the intestine at the points of entrance of the blood vessels. Thus, they are analagous to the false diverticula most commonly encountered in the colon. These thin outpouchings lack a muscular component and as a result are completely atonic dilatations. The peristaltic activity of the small intestine and the fluid nature of the chyme tends to fill these pouches. Emptying also depends on intestinal movement but this is difficult because of the narrow stomata. Consequently they are susceptible to inflammation and trauma.

A wide variety of complications other than those already noted have been described, including adhesions or stricture which may produce intestinal obstruction, torsion, or volvulus (D'Abreu, 1944; Johnson, 1945; Porter, 1946), a functional type of intestinal obstruction with no evidence of mechanical blockage and a characteristic thickening of small bowel (Gordinier and Sampson, 1906; Benson, Dixon, and Waugh, 1943; Phillips, 1953; Nelson,
Schmitz, and Narsete, 1954; Lowe and Wilkinson, 1959), cyst formation due to occlusion of the mouth of a sac (Gordinier and Sampson, 1906), concretion formation (Klidjian, 1946; Armitage, Fowweather and Johnstone, 1950), pneumoperitoneum (Nanson and Dragan, 1956), traumatic rupture (Butler, 1933; Bagley and Bagley, 1946), diverticulitis (Butler, 1933; Orr and Russell, 1951 ; Phillips, 1953), intussusception (River and Silverstein, 1951), carcinoma within the diverticulum (Benson, Dixon, and Waugh, 1943), enterolith formation (Renaud and Renaud, 1921; Terry and Mugler, 1921), and intestinal obstruction due to an enterolith being dislodged into the lumen of the bowel (Watson, 1924; Christ, 1932). Foreign bodies may lodge in diverticula, and reports have included ingested bones (Ogloblina, 1931), food particles (Treves, 1960), and parasites (Goinard and Courrier, 1929; Rosedale, 1935). In our 30 patients, complications were observed only in five, an incidence similar to that reported by Bastin and Mayo (1952) and by Silen, Brown, Orloff, and Watkins (1960). The antecedent histories in these five patients, and in the others and in many patients reported in the literature are almost certainly the result of similar but less severe complications than those noted above. For example, the persistent burning pain noted by some patients could be due to chronic low-grade infection of a diverticulum: the sudden onset of pain following food may be due to sudden distension or impaction, and pain related to posture certainly suggests the possibility of intermittent volvulus or obstruction. The intermittent nature of all these symptoms with variation in frequency and severity in the same patient probably accounts for the common designation of 'vague dyspepsia'. Because one symptom may be more prominent in any one patient does not detract from the conclusion that they are the direct result of the jejunal diverticulosis. The high incidence of one or other metabolic abnormality and their disappearance, together with considerable improvement of symptoms following antibiotic therapy when many other remedies have failed, strongly support the conclusion that the diverticula or their complications are responsible for the multiple disturbances. Doubtless in some patients diverticula are asymptomatic, but these are a small proportion of the patients who present at hospital for investigation. This would be smaller still with prolonged observation, for the diverticula remain a potential source of disability.

Metabolic abnormalities vary from patient to patient, suggesting that differences in the site or size of the diverticula may be of importance in their production. They seem to be more common in patients with multiple and large diverticula but they also occur in patients with solitary or small diverti- 
cula. Probably infection plays an important role in determining those that do occur. The obvious improvement in laboratory tests of 'absorption' following the administration of tetracycline and aureomycin supports the suggestion of infection of these atonic mucosal dilatations.

Johnson and Wysor (1961) suggested the possibility that the 'endodiverticula flora' might produce chronic inflammation or that bacterial metabolites might evoke an allergic response in the adjacent jejunal mucosa and the subsequent inflammation or oedema would interfere with absorption. However, jejunal biopsy in eight patients who had severe absorptive defects showed little evidence of abnormality, cellular infiltration or oedema being seen in only three patients. Schiffer, Faloon, Chodos, and Lozner (1962) reported changes in the jejunal biopsy of a patient with jejunal diverticulosis, macrocytic anaemia, and steatorrhoea. They considered the findings similar to those found in coeliac disease, non-tropical sprue and tropical sprue, and the neomycin malabsorptive states. However, only one third of the villi in the biopsy specimen were abnormal, which would be an unusual finding in an untreated patient with coeliac disease or non-tropical sprue.

In the majority of patients the site of the diverticula is limited to the duodenum and jejunum. As a result it might be expected that malabsorption would predominantly affect those substances normally absorbed in the proximal small intestine, such as iron (Hahn, Bale, Lawrence, and Whipple, 1939; Moore, Dubach, Minnich, and Roberts, 1944), glucose, xylose (Schedl and Clifton, 1961), folic acid (Cox, Cooke, Meynell, and Gaddie, 1958), and fat (Borgström, Dahlqvist, Lundh, and Sjövall, 1957; Turner, Cox, Balint, Pirrie, Fletcher, and Huang, 1960; Booth, Read, and Jones, 1961). Evidence of iron deficiency and a flat glucose tolerance curve was found on only one occasion and whilst the frequency of malabsorption of folic acid, fat, and xylose was much greater, there was no consistent correlation between them. Some of the inconsistencies in these patients might be explained by better absorption in the duodenum or the ability of the ileum to compensate for the shortcomings of the proximal small intestine. The discrepancy of the abnormal folic acid excretion tests in six patients and only one of them having clinical evidence of folic acid deficiency may be explained by the production of pteroylglutamates by the organisms infecting the blind loops (Doig and Girdwood, 1960). Dawson and Isselbacher (1960) have postulated that bacteria may induce the conversion of conjugated bile salts to toxic unconjugated salts which would interfere with fat absorption. Most of the available evidence, however, suggests that the malabsorption is due to a disturbance of the physico-chemical composition of the chyme causing interference with digestion and absorption in the neighbourhood of the infected diverticula.

No mention has been made of the products of protein digestion which are also absorbed in the proximal small intestine (Borgström, Dahlqvist, Lundh, and Sjövall, 1957). Though the frequency of hypoalbuminaemia might be thus explained, the rapid fall in serum albumin which was occasionally observed in patients with severe exacerbation of abdominal symptoms suggests that an enteropathic loss is the more common mechanism.

The occurrence of impaired absorption of vitamin B12 offers firm support for regarding the upset of physicochemical relationships in the lumen of the gut as the main cause for the malabsorption. The absorption of vitamin B12 requires an adequate secretion of intrinsic factor. In three of the patients presented here normal absorption was restored when $58 \mathrm{CoB} 12$ was administered with intrinsic factor and it was concluded that they were suffering from pernicious anaemia complicated by jejunal diverticulosis.

Other patients had either severely impaired or subnormal $58 \mathrm{CoB} 12$ absorption which was improved by the administration of antibiotics, an effect initially recorded by Badenoch, Bedford, and Evans (1955) and subsequently confirmed by many workers. The same effect with antibiotics has been noted in the 'blind loop syndrome' which includes patients with intestinal stricture, fistulae, enteroanastomoses, and surgically produced blind loops (Halsted, Gasster, and Lewis, 1956). The beneficial effects have been attributed either to sterilization or to alteration of the bacterial flora in the stagnant loops or areas of the small intestine which in some ways allows the resumption of normal $58 \mathrm{CoB} 12$ absorption. However, most blind loops or strictures are situated in the ileum. The ileum is also responsible for the absorption of vitamin B12 (Booth, Chanarin, Anderson, and Mollin, 1957; Cooke. Cox, Meynell, and Gaddie, 1957; Cox. Meynell, Cooke, and Gaddie, 1958; Booth and Mollin, 1959). On the other hand, in the patients presented here with diverticula of the small intestine and in the majority of patients recorded in the literature suffering from disorders associated with malabsorption of vitamin B12, the diverticula were limited to the duodenum and jejunum. It has been suggested that severe infection of these jejunal diverticula and the subsequent overspill down the remainder of the intestine might account for this disturbance. This seems improbable, for in some patients the only absorptive faculty that was affected was that of $58 \mathrm{CoB} 12$. The hypothesis has been put forward that the infecting organism has an avidity 

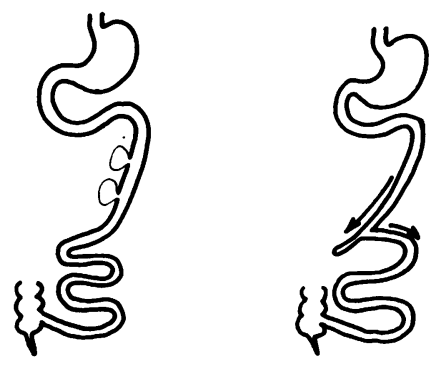

FIG. 7. Diagrammatic representation of:

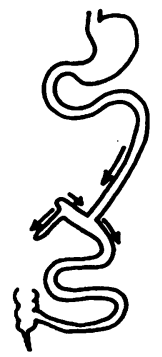

(1) Jejunal diverticulae.

(2) The blind loop of Cameron, Watson, and Witts (1949) in the middle third of small intestine designed to fill by its own peristalsis.

(3) The bypass operation as performed by Donaldson (1962).

for vitamin B12, since Doig and Girdwood (1960) demonstrated a high uptake of radioactive $\mathrm{B} 12$ by organisms cultured from the contents of human intestinal diverticula.

At first sight, animal experimentation appears to have simulated the condition produced by the diverticula. Cameron, Watson, and Witts (1949) demonstrated the development of a macrocytic anaemia in rats following the production of blind loops of small intestine which filled by peristalsis, provided that they were situated in the upper or middle third of the gut (Fig. 7). The bacterial flora of these blind loops resembled that of the caecum. Donaldson (1962), in similar experiments with rats, demonstrated the beneficial effects of antibiotics and also the uptake of vitamin B12 by the organisms in the stagnant loops. There are, however, certain important features that differ in these experimentally produced states from those in man with jejunal diverticulosis. To be effective in rats the self-filling loops must be situated above the lower third of the small intestine: the site of maximum absorption of vitamin B12 in rats is situated in the middle third. The blind loop is so designed that it becomes enormously distended (Cameron, Watson, and Witts, 1949; Ungley, Cox, Schofield, and Thompson, 1953); the contents are extremely faeculent and affect the small intestine proximal from the blind loop. This contrasts strongly with the mechanics of the small intestinal diverticula into which food does not normally pass directly and is much more comparable to the experimental bypassing of an infected blind loop devised by Donaldson. Such bypassing restores vitamin B12 absorption to normal despite the fact that the blind loop itself is still infected. This rules out the hypothesis that absorption of toxins from the infected loop either increases the utilization or interferes with, absorption of vitamin B12 (Ungley, Cox, Schofield, and Thompson, 1953). This experiment also disposed of the hypothesis put forward by Drexler (1958) that indole compounds possess an inhibitory effect on the utilization of vitamin B12 since rats with a bypassed blind loop still have a raised indole excretion. Two other contrasts between the experimentally produced blind loop in rats and diverticula in man are the poor response to vitamin B12 and good response to folic acid noted in rats and the lack of effect of non-absorbable antibiotics in man noted by Halstead, Lewis, and Gasster (1956) and by Watkinson, Feather, Marson, and Dossett (1959).

A further possibility exists which could account for the impaired absorption of vitamin B12 in some patients with jejunal diverticulosis. It has long been recognized that intrinsic factor is rapidly destroyed in an acid medium (Castle and Townsend, 1929) and recently investigation as to the nature of intrinsic factor, apparently a mucoprotein, led one to question why it is not destroyed in the intestinal tract. Von Bonsdorff (1947) demonstrated that in fish infestation with tape worms has to be maximal in the proximal small intestine to produce a megaloblastic anaemia and this does not occur when the infestation is limited to the lower half of the small intestine. In jejunal diverticula Badenoch, Bedford, and Evans (1955) found that increasing quantities of intrinsic factor improved the absorption of vitamin B12 in those patients with malabsorption of this vitamin with jejunal diverticula. Mcintyre, Sachs, Krevans, and Conley (1956) observed malabsorption of $58 \mathrm{CoB} 12$ in some patients with pancreatic disease. Nieweg, Abels, Veeger, and Hellemans (1962) found that, though pancreatin improved absorption in some patients with pancreatic disease, more marked improvement was noted when sodium bicarbonate was administered. In three of the patients reported here absorption was inproved following administration of alkalis. Thus the possibility arises that in the duodenum and jejunum not only is intrinsic factor protected by the rise in $\mathrm{pH}$ but it combines with vitamin B12 to form a stable complex which can later be absorbed in the ileum. This mechanism would be upset in jejunal diverticulosis, pancreatic disease, and possibly in some cases of the blind loop syndrome following a partial gastrectomy. This hypothesis would imply that this disorder of absorption is the result of disturbances in the upper small intestine, the site of the diverticula. The beneficial effects of antibiotics suggest that infection plays a major role. The production of an acid reaction in the jejunum by the infection may be one way in which the combination of vitamin $\mathrm{B} 12$ and intrinsic factor in the lumen is rendered ineffective.

The cause of the neurological disturbances is probably multiple. There is no record in the litera- 
ture of detailed examination of the spinal cord. Subacute combined degeneration of the cord has been recorded and on clinical grounds from the response to therapy the diagnosis seems fully justified. Four of the patients presented here fulfilled the normal criteria for this diagnosis. Five of the remaining patients had objective evidence of a peripheral neuropathy and posterior column disease confined to the lower limbs. Each of these patients complained of paraesthesiae in the feet and had reduced or absent ankle jerks, rhombergism, a wide-based gait, and slight blunting of peripheral sensation. Two of these patients actually developed the neuropathy whilst receiving adequate therapy with vitamin $\mathrm{B} 12$.

The findings resemble the neuropathy encountered in adult coeliac disease. This condition also does not respond to therapy with vitamin B12 and has been called pseudo tabes by Spencer (1957). The aetiology is not known, and in adult coeliac disease the prognosis is poor but in diverticulosis of the small intestine the progress does appear to have been halted by the administration of antibiotics.

We wish to thank the physicians and surgeons of the United Birmingham Hospitals for allowing us to investigate their patients. We are particularly indebted for the great interest and cooperation of the consultant radiologists of the General Hospital, Drs. Bishop, Hutton, Toye, and Jacobs, without whom this study could not have been made. One of us (D.J.F.) was in receipt of a personal grant from the Endowment Medical Research Fund of the United Birmingham Hospitals. We are indebted to Lederle Research Laboratories for generous supplies of intrinsic factor.

\section{REFERENCES}

Armitage, G., Fowweather, F. S., and Johnstone, A. S. (1950) Observations on bile-acid enteroliths with an account of a recent case. Brit. J. Surg., 38, 21-25.

Badenoch, J., and Bedford, P. D. (1954). Massive diverticulosis of the upper intestine presenting with steatorrhoea and megaloblastic anaemia. Quart. J. Med., 23, 462.

- , - and Evans, J. R. (1955). Massive diverticulosis of the small intestine with steatorrhoea and megaloblastic anaemia. Ib d., 24, 321-330.

Bagley, W. R., and Bagley, C. M. (1946). Ruptured diverticulum of jejunum. Minn. Med., 29, 691-692.

Barker, W. H., and Hummel, L. E. (1939). Macrocytic anemia in association with intestinal strictures and anastomoses. Bull. Johns Hopk. Hosp., 64, 215-254.

Bastin, R. H. Jr., and Mayo, C. W. (1952). Jejunal diverticulosis: a clinical study of 87 cases. Surg. Clin. N.Amer., 32, 1185-1196.

Benson, R. E., Dixon, C. F., and Waugh, J. M. (1943). Nonmeckelian diverticula of the jejunum and ileum. Ann. Surg., 118, 377-393.

Blachford, R. D., and Dawson, D. W. (1956). Association of jejunal diverticulosis with macrocytic anaemia. Brit. med. J., 1 , 1407-1408.

Booth, C. C., Chanarin, I., Anderson, B. B., and Mollin, D. L. (1957). The site of absorption and tissue distribution of orally administered ${ }^{58} \mathrm{Co}$-labelled vitamin $\mathrm{B} 12$ in the rat. Brit. $J$. Haemat., 3, 253-261.

- and Mollin, D. L. (1959). The site of absorption of vitamin B12 in man. Lancet, 1, 18-21.
Booth, C. C., Read, A. E., and Jones, E. (1961). Studies on the site of fat absorption. (1) Sites of absorption of increasing doses of ${ }^{131}$ I-labelled triolein in the rat. Gut, 2, 23-31.

Borgström, B., Dahlqvist, A., Lundh, G., and Sjövall, J. (1957). Studies of intestinal digestion and absorption in the human. J. clin. Invest., 36, 1521-1536.

Braithwaite, L. R. (1923). A case of jejunal diverticula. Brit. J. Surg. 11, $184-188$.

Butler, R. W. (1933). Observations upon multiple intra-mesenteric diverticula of the small intestine. Ibid., 21, 329-346.

- (1937). Traumatic rupture of intramesenteric diverticula of the jejunum. Ibid., 25, 277-279.

Cameron, D. G., Watson, G. M., and Witts, L. J. (1949). The experimental production of macrocytic anemia by operations on the intestinal tract. Blood, 4, 803-815.

Case, J. T. (1920). Diverticula of small intestine, other than Meckel's diverticulum. J. Amer. med. Ass., 75, 1463-1470.

Castle, W. B., and Townsend, W. C. (1929). Observations on the etiologic relationship of achylia gastrica to pernicious anemia. II. The effect of administration to patients with pernicious anemia of beef muscle after incubation with normal human gastric juice. Amer. J. med. Sci., 178, 764-777.

Christ, A. (1932). Multiple Divertikel des Jejunum. Anatomische und klinische Beiträge zur Kenntnis eines seltenen krankheitsbildes. Dtsch. Z. Chir., 236, 560-570.

Cooke, W. T., Cox, E. V., Meynell, M. J., and Gaddie, R. (1957). Importance of the ileum in the absorption of vitamin B12. Lancet, 2, 1231.

Cooper, A. (1807). The Anatomy and Surgical Treatment of Crural and Umbilical Hernia, p. 87. Longman, London.

Cox, E. V., Meynell, M. J., Cooke, W. T., and Gaddie, R. (1958). The folic acid excretion test in the steatorrhea syndrome. Gastroenterology, 35, 390-397.

Crawford, D. W., and Freeman, R. M. (1961). Megaloblastic anemia in association with jejunal diverticula. Arch. intern. Med., 108, 775-780.

D'Abreu, F. (1944). An unusual case of diverticulum of the small intestine. Brit. J. Surg., 31, 408-409.

Dawson, A. M., and Isselbacher, K. J. (1960). Studies on lipid metabolism in the small intestine with observations on the role of bile salts. $J$. clin. Invest., 39, 730-740.

Delaney, W. E., and Hedges, R. C. (1962). Acquired ileal diverticulosis and hemorrhagic diverticulitis. Gastroenterology, 42, 56-59.

Denkewalter, F. R., Molnar, W., and Horava, A. P. (1958). Massive gastro-intestinal hemorrhage in jejunal diverticulosis. Ann. Surg., 148, 862-866.

Dick, A. P. (1955). Association of jejunal diverticulosis and steatorrhoea. Brit. med. J., 1, 145-148.

Doig, A., and Girdwood, R. H. (1960). The absorption of folic acid and labelled cyanocobalamin in intestinal malabsorption. Quart. J. Med., 29, 333-374.

Donaldson, R. M. Jr. (1962). Malabsorption of $\mathrm{Co}^{80}$-labelled cyanocobalamin in rats with intestinal diverticula. I. Evaluation of possible mechanisms. Gastroenterology, 43, 271-281.

Drexler, J. (1958). Effect of indole compounds on vitamin B12 utilization. Blood, 13, 239-244.

Edwards, H. C. (1939). Diverticula and Diverticulitis of the Intestine. Wright, Bristol.

Faber, K. I. (1895). Perniciøs anaemia som følg of tarmlibelse. Hosp. tid. Kjobenh., 4, R. 3, 601.

Fone, D. J., Cooke, W. T., Meynell, M. J., and Harris, E. L. (1961) $\mathrm{Co}^{58} \mathrm{~B} 12$ absorption (hepatic surface count) after gastrectomy ilial resection and in coeliac disorders. Gut, 2, 218-224.

Fowler, D. I. (1961). Unpublished observations.

Fowler, D., and Cooke, W. T. (1960). Diagnostic significance of D-xylose excretion test. Gut., 1, 67-70.

Friedlander, P. H., and Gorvy, V. (1955). Steatorrhoea: a review of 40 patients, with particular reference to diagnosis. Brit. med. J.. 2, 809-812.

Gellman, D. D. (1956). Diverticulosis of the small intestine with steatorrhoea and megaloblastic anaemia. Lancet, 2, 873-874.

Godard, H., Bourdial, and Zourekatis, T. (1932). Un cas de diver ticulose jéjuno-iléale. Ann. Anat. path., 9, 311-315.

Goinard, P., and Courrier, R. (1929). Sur la constation de parasites dans des diverticules multiples du jéjunum. Ibid., 6, 189-196.

Gordinier, H. C., and Sampson, J. A. (1906). Diverticulitis (not Meckel's) causing intestinal obstruction. Multiple mesenteric (acquired) diverticula of the small intestine. J. Amer. med. Ass., 46, $1585-1590$. 
Hahn, P. F., Bale, W. F., Lawrence, E. O., and Whipple, G. H. (1939). Radioactive iron and its metabolism in anemia. Its absorption, transportation, and utilization. J. exp. Med., 69, 739-753.

Halsted, J. A., Lewis, P. M., and Gasster, M. (1956). Absorption of radioactive vitamin $B 12$ in the syndrome of megaloblastic anemia associated with intestinal stricture of anastomosis. Amer. J. Med., 20, 42-52.

Harvey, E. A., and Murphy, W. P. (1933). Pernicious anemia without achlorhydria, case report. Ann. intern. Med., 6, 1393-1406.

Johnson, J. A. (1945). Diverticula of the jejunum. Minn. Med., 28, 395-396.

Johnson, P. M., and Wysor, W. G. (1961). Mimetic aspects of small intestinal diverticulosis-a report of four cases. Arch. intern. Med., 108, 370-375.

King, E. J., Haslewood, G. A. D., Delory, G. E., and Beall, D. (1942). Micro-chemical methods of blood analysis. Lancet, 1, 207-209.

Klidjian, A. (1946). Jejunal diverticulosis complicated by haemorrhage. Brit. med. J., 1, 683-684.

Kozinn, P. J., and Jennings, K. G. (1941). Jejunal diverticulitis: its occurrence in a two year old girl. Amer. J. Dis. Child., 62 , 620-623.

Kozoll, D. D., McMahon, J. A., and Kiely, J. P. (1950). Massive gastrointestinal hemorrhage due to jejunal diverticula. J. Amer. med. Ass., 142, 1258-1262.

Krevans, J. R., Conley, C. L., and Sachs, M. V. (1956). Radioactive tracer tests for the recognition and identification of vitamin B12 deficiency states. J. chron. Dis., 3, 234-252.

Lee, R. E., and Finby, N. (1958). Jejunal and ileal diverticulosis. Arch. intern. Med., 102, 97-102.

Lowe, K. J., and Wilkinson, S. A. (1959). Recurrent ileus in a case of jejuanl diverticulosis. Gastroenterology, 36, 524-527.

McCollum, J. K. (1959). Intestinal diverticula. Brit. med. J., 2, 34-38.

McIntyre, P. A., Sachs, M. V., Krevans, J. R., and Conley, C. L. (1956). Pathogenesis and treatment of macrocytic anemia: information obtained with radioactive vitamin B12. A.M.A. Arch. intern. Med., 98, 541-549.

Meckel, J. F. (1812-16). Handbuch der pathologischen Anatomie, 3 vols. Reclam, Leipzig. Quoted by Osler (1881).

Meynell, M. J., Cooke, W. T., Cox, E. V., and Gaddie, R. (1957). Serum-cyanocobalamin level in chronic intestinal disorders. Lancet, 1, 901-904.

Montuschi, E. (1949). Jejunal insufficiency with hypoproteinaemic oedema. [Brief case report.] Proc. roy. Soc. Med., 42, 868-869.

Moore, C. V., Dubach, R., Minnich, V., and Roberts, H. K. (1944). Absorption of ferrous and ferric radioactive iron by human subjects and by dogs. J. clin. Invest., 23, 755-767.

Nanson, E. M., and Dragan, G. E. (1956). A spontaneous pneumoperitoneum due to jejunal diverticulosis. Ann. Surg., 143, 112116.

Nelson, P. A., Schmitz, R. L., and Narsete, E. M. (1954). Jejunal diverticulosis complicated by chronic "nonmechanical" obstruction. Illinois med. J., 106, 371-374.

Nieweg, H. O., Abels, J., Veeger, W., and Hellemans, N. (1962). The defective absorption of vitamin B12 in pancreatic insufficiency. In Vitamin B12 and Intrinsic Factor. 2. Europaisches Symposion, edited by H. C. Heinrich, pp. 610-612. Enke, Stuttgart.

Noer, T. (1960). Non-Meckelian diverticula of the small bowel: the incidence in an autopsy material. Acta chir. scand., 120, 175-179.

Ogloblina, S. (1931). Multiple Divertikel des Dünndarms. [Abstr. of (1930). Zh. sovrem. Khir., 5, 105.] Zbl. Chir., 58, 316.

Orr, I. M., and Russell, J. Y. W. (1951). Diverticulosis of the jejunuma clinical entity. Brit. J. Surg., 39, 139-147.

Osler, W. (1881). Notes on intestinal diverticula. Ann. anat. Surg., 4, 202-207.

Phillips, J. H. C. (1953). Jejunal diverticulosis. Some clinical aspects. Brit. J. Surg., 40, 350-354.

Polachek, A. A., Pijanowski, W. J., and Miller, J. M. (1961). Diverticulosis of the jejunum with macrocytic anemia and steatorrhea. Ann. intern. Med., 54, 636-645.

Porter, H. W. (1946). A case of a chronic volvulus of the jejunum due to multiple jejunal diverticula. Brit. J. Surg., 34, 218-219.

Rankin, F. W., and Martin, W. J. Jr. (1934). Diverticula of the small bowel. Ann. Surg., 100, 1123-1135.

Renaud, M., and Renaud, B. (1921). Deux diverticules de l'intestin. Bull. Soc. Anat. (Paris), 91, 220.
River, L. P., and Silverstein, J. (1951). Diverticula of the small intestine: Report of case of jejunal diverticulum. J. int. Cell. Surg., 15, 347-351.

Rosedale, R. S. (1935). Jejunal diverticulosis. Surg. Gynec. Obstet., 61, 223-228.

Schedl, H. P., and Clifton, J. A. (1961). Kinetics of intestinal absorption in man: Normal subjects and patients with sprue. J. clin. Invest., 40, 1079-1080.

Schiffer, L. M., Faloon, W. W., Chodos, R. B., and Lozner, E. L. (1962). Malabsorption syndrome associated with intestinal diverticulosis. Report of a case with jejunal biopsy. Gastroenterology, 42, 63-68.

Scudamore, H. H., Hagedorn, A. B., Wollaeger, E. E., and Owen, C. A. Jr. (1958). Diverticulosis of the small intestine and macrocytic anem a with report of 2 cases and studies on absorption of radioactive vitamin B12. Ibid., 34, 66-82.

Spencer, W. (1957). Neurological manifestations in the malabsorption syndrome. J. Mt. Sinai Hosp., 24, 331-345.

Shutkin, M. W. (1945). Diverticulitis of the jejunum with perforation. Gastroenterology, 5, 102-105.

Silen, W., Brown, W. H., Orloff, M. J., and Watkins, D. H. (1960). Complications of jejunal diverticulosis: a report of three cases. Arch. Surg., 80, 597-601.

Spang, A. (1954). Ungewöhnlech ausgedehnte Diverticulosis des Dünndarms mit megaloblastischer Anämie. Fortschr. Röntgenstr., 81, 55-58.

Spray, G. H. (1955). An improved method for the rapid estimation of vitamin B12 in serum. Clin. Sci., 14, 661-667.

Spriggs, E. I., and Marxer, O. A. (1925). Intestinal diverticula. Quart. J. Med., 19, 1-34.

Stiven, H. E. S. (1934). Jejuno-ileal diverticulitis. Lancet, 2, 704-705.

Strömme, A. (1956). Fluid levels in diverticula of the small intestine: a radiological sign simulating obstruction. Brit. J. Radiol., 29, 574-57.6

Terry, W. I., and Mugler, F. R. (1921). Diverticula of the jejunum. Arch. Surg. (Chicago), 2, 347-353.

Townsend, S. R., and Cameron, D. G. (1957). Megaloblastic anemia associated with diverticula of the small bowel. Amer. J. Med., 23, 668-670.

Treves, F. (1902). Intestinal Obstruction: Its Varieties with Their Pathology, Diagnosis and Treatment. Wood, New York.

Turner, D. A., Cox, E. V., Balint, J. A., Pirrie, R., Fletcher, R. F., Huang, E., and Cevallos, W. H. (1960). Digestion and absorption of fat after a normal meal. Fed. Proc., 19, 876-883.

Ungley, C. C., Cox, E. V., Schofield, B., and Thompson, R. B. (1953). Megaloblastic anaemia following operations in the intestine. Gastroenterologia (Basel), 79, 338-342.

van de Kamer, J. H., ten Bokkel Huinink, H., and Weyers, H. A. (1949). Rapid method for the determination of fat in feces. J. biol. Chem., 177, 347-355.

Verster, R. S. (1937). Diverticulosis of the small intestine. S. Afr. med. J., 11, 838-841.

Von Bonsdorff, B. (1947). The site of infestation with fish tapeworm determined by means of intestinal intubation. Diphyllobotrium latum and pernicious anemia. Acta med. scand., 129, 213-233.

Walker, R. M. (1954). The complications of acquired diverticulosis of the jejunum and ileum. Brit. J. Surg., 32, 457-463.

Warthen, H. J. (1953). Diverticulosis of the jejunum-a frequently overlooked source of gastrointestinal bleeding. Virginia med. Mth., 80, 203-205.

Waterson, A. P. (1952). Jejunal diverticulosis with haemorrhage. Lancet, 2, 1053-1054.

Watkinson, G., Feather, D. B., Marson, F. G. W., and Dossett, J. A. (1959). Massive jejunal diverticulosis with steatorrhoea and megaloblastic anaemia improved by excision of diverticula. Brit. med. J., 2, 58-62.

Watson, C. M. (1924). Diverticula of jejunum-a case with enterolith causing intestinal obstruction. Surg. Gynec. Obstet., 38, 67-71.

Weichselbaum, T. E. (1946). An accurate and simple method for the determination of proteins in small amounts of blood serum and plasma. Tech. Bull. Reg. Med. Technol., 7, 40-49.

Welbourn, R. B., Nelson, M. G., and Zacharias, F. J. (1956). Megaloblastic anaemia following gastric resection: report of ten cases. Brit. J. Surg., 43, 422-428.

Wilkerson, J. H., and Coffman, R. (1948). Multiple diverticula of the jejunum. Amer. J. Surg., 75, 733-738.

Wilkinson, R. W. (1955). Subacute combined degeneration of the spinal cord with megaloblastic anaemia due to spontaneous ileocolic fistula. Lancet, 1, 74-75. 